\title{
EFFECT OF VIBRATION ON SURFACE ROUGHNESS IN FINISH TURNING: SIMULATION STUDY
}

\author{
Kang, W. T.; Derani, M. N. \& Ratnam, M. M." \\ School of Mechanical Engineering, Engineering Campus, Universiti Sains Malaysia, \\ 14300 Nibong Tebal, Penang, Malaysia \\ E-Mail: mmaran@usm.my ( ${ }^{\#}$ Corresponding author)
}

\begin{abstract}
This paper presents the results of simulation analyses carried out to investigate the effect of adding controlled vibration of varying amplitudes and frequencies onto simulated workpiece profiles on surface roughness. The surface profiles were generated using the nose edge image of a real cutting tool insert at various stages of wear. The invariant moment sub-pixel edge detection method was used to extract the precise tool nose profile. The extracted nose profile was duplicated 20 times to generate the simulated workpiece profile. Vibration signals in the form of sine waves of amplitudes 0 to $50 \%$ of the peak-tovalley height of the original workpiece profile and various frequencies were added to the simulated profile. Noise signals emanating from real machining were also added to the original profile to investigate their effect on roughness. The simulation study has shown that average roughness may increase continuously or fluctuate randomly depending on the magnitude of vibration added to the vibration-free workpiece profile. In the absence of vibration, the surface roughness of the workpiece decreases due to flattening effect of the tool nose during early stages of tool wear.

(Received in August 2020, accepted in October 2020. This paper was with the authors 2 weeks for 1 revision.)
\end{abstract}

Key Words: Surface Roughness, Vibration, Simulation, Tool Wear

\section{INTRODUCTION}

Turning is a common machining operation, whereby a single-point cutting tool is moved longitudinally along a rotating workpiece, to shape the final product [1-2]. The quality of the finished product is measured in terms of its dimensional accuracy and surface integrity. Several factors work in combination to affect the final product quality. These include the condition of machine tool, machining parameters (feed rate, cutting speed and depth-of-cut), machining conditions (dry or wet turning), type and condition of cutting tool, cutting tool material, and workpiece material (hardness, granularity, thermal conductivity etc.). Ratnam [3] provided a detailed overview of the various factors affecting surface finish quality during finish turning.

One of the main factors that affect the surface roughness of turned products is tool wear. Since the cutting tool is in direct contact with the workpiece during machining, deterioration of tool due to wear will have direct and significant effect on surface roughness. In an ideal case, the profile of the tool nose is replicated onto the surface of workpiece, thus forming the familiar tool marks observed on turned parts. As the curved tool nose becomes increasingly flattened due to abrasive wear, the peak-to-valley height of the roughness profile will decrease progressively, thus decreasing the average roughness. However, when the tool gets badly worn, other effects, such as vibration, edge build-up, scouring and tear, can affect the surface integrity of the workpiece in unpredictable ways. A decrease in the average roughness $\left(R_{a}\right)$ was reported by Shahabi and Ratnam [4] during the early stages of machining, followed by an increase in $R_{a}$ when machining was prolonged. Niaki and Mears [5] reported that $R_{a}$ fluctuated randomly as tool wear increased during turning of Inconel-718 hard-to-machine alloy, while Khan et al. [6] and Sani et al. [7] found that $R_{a}$ increased continuously during machining of alloy and lowcarbon steel, respectively. Although it is difficult to pin-point a single factor that causes such differences, vibration is known to be a dominant factor that affects surface roughness in all turning operations [8]. 
Özbek and Saruhan [9] measured the cutting tool vibration amplitude, temperature, tool wear and surface roughness under dry and minimum quantity lubrication (MQL) turning of AISI D2 cold work tool steel. The authors used two different types of tools, one coated by chemical vapour deposition (CVD) while another coated by physical vapour deposition (PVD). Their results showed that when turning using CVD inserts at a feed rate of $120 \mathrm{~m} / \mathrm{min}$ the tool vibration in feed direction decreased by $20 \%$ under MQL compared to dry turning. There was a corresponding decrease in surface roughness by $87 \%$. The authors attributed the higher vibration during dry turning to the increase in tool wear. The use of PVD tools produced vibration amplitudes lower by as much as $20 \%$ due to corresponding decrease of about $21 \%$ in flank wear, confirming that tool wear has direct effect on vibration. The average roughness decreased by $82 \%$, confirming that vibration and tool wear have significant influence on surface roughness, whereby roughness increased as vibration amplitude increased.

García Plaza and Núñez López [10] applied singular spectrum analysis (SSA) to vibration signals produced in workpiece-cutting tool interaction for the enhanced monitoring of surface roughness $\left(R_{a}\right)$. The vibration signals were measured using triaxial accelerometers mounted near to the contact area of workpiece-tool interface. Signal along the tool feed direction was found to be the primary data source for monitoring surface roughness. The authors showed that the frequency ranges in the vibration signal can be used effectively to predict surface roughness. In a related work [11], the authors used wavelet packet transform to extract features from the vibration signal that were correlated with surface roughness. Horváth and Lukács [12] developed force models in precision turning of various materials, though vibration and surface roughness were not included in their models. Özdemir [13] modelled effect of machining parameters on surface roughness and showed that the dominant parameters affecting roughness were feed rate and nose radius. Rifai et al. [14] and Mia and Dhar [15] applied artificial intelligence methods for predicting surface roughness. However, the influence of vibration on surface roughness was not investigated in these studies.

Although several authors have shown that surface roughness can be predicted using vibration signals [16-21], a systematic study to understand the influence of vibration alone on surface roughness of workpiece has not been reported. Previous simulation studies on the effect of vibration has been limited to drilling [22] or turning without analysis of its effect on surface roughness [23]. In this paper, a detailed simulation analysis was carried to understand how controlled vibration can affect surface roughness of the workpiece during turning.

\section{METHODOLOGY}

\subsection{Workpiece surface generation in MATLAB}

The workpiece surface profile was generated digitally in MATLAB (R2018b) using the nose profile of a real cutting tool (Fig. 1). The tool was mounted on Pinacho S90 lathe, and captured at various intervals of machining, including one before machining. The tool was cleaned using compressed air and a microfiber cloth wetted in acetone to remove chips and dust after each machining pass. A high-resolution (18 MP) digital-single-lens-reflex (DSLR) camera (CANON EOS700D) fitted with EF100 mm f/2.8 Canon macro lens (magnification ratio of 1:1), was used to capture low depth-of-field silhouette images of the tool with the aid of diffused backlighting. High megapixel camera enabled high resolution images to be captured for precise edge location. The scaling factors needed to convert the image coordinates in pixels to real-world coordinates in millimetres were determined using a $4.8 \mathrm{~mm}$ diameter pin gauge (Mitutoyo Inc., Japan). The invariant moment sub-pixel edge detection method [24] was used to extract the nose edge to sub-pixel accuracy (Fig. $1 \mathrm{a}$ ). The image pre-processing was limited to only intensity normalization using contrast stretching to avoid loss of image data. 

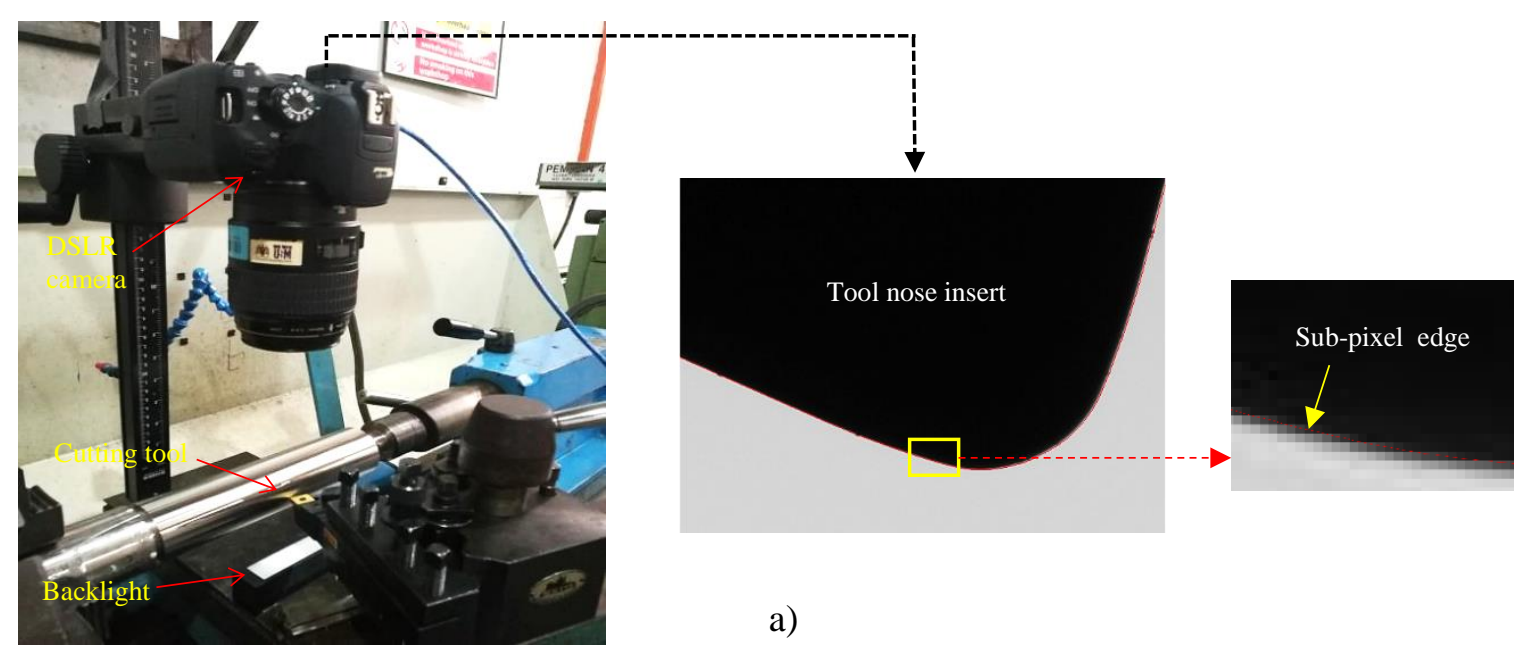

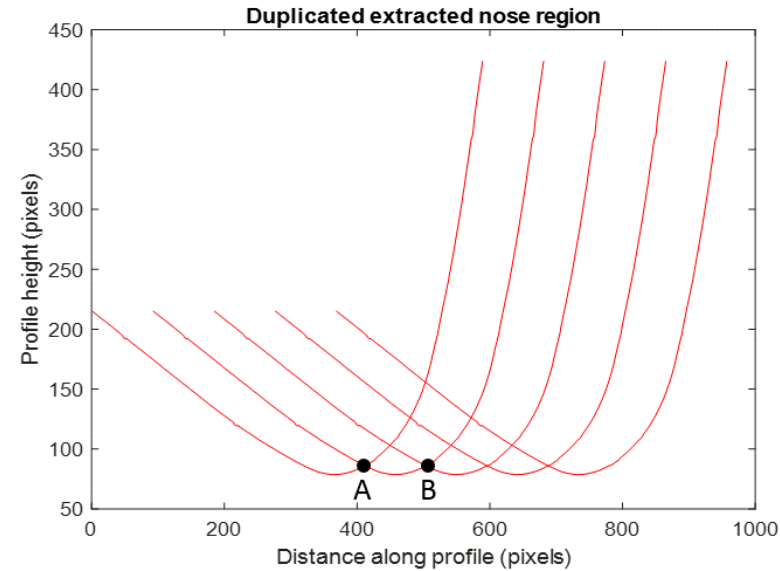

b)

a)

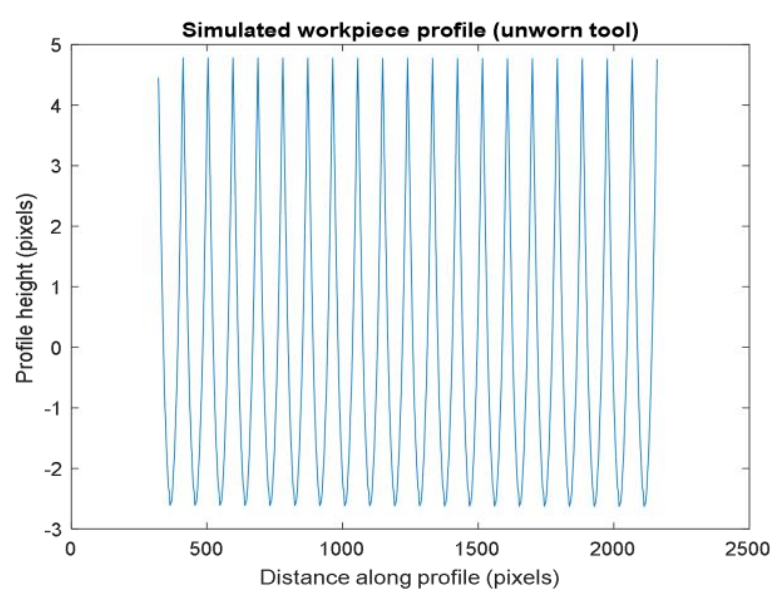

c)

Figure 1: a) Machining setup and tool insert edge (inset image shows the subpixel edge), b) duplicated profile using extracted nose, c) simulated workpiece surface profile.

In the sub-pixel edge detection method, the edge is defined between series of pixels at one level of intensity $h_{1}$ followed by pixels at another level $h_{2}$. The first three moments $m_{1}, m_{2}$ and $m_{3}$ of the input data are given by threshold independent method based on grey level moment equations. The $i^{\text {th }}$ moment of the input grey level data sequence $x_{j}$ is given by [24]:

$$
\bar{m}_{i}=\frac{1}{n} \sum_{j=1}^{n}\left(x_{j}\right)^{i}
$$

where $x_{1}, x_{2}, \ldots, x_{n}$ are pixel intensities, and $n$ is the number of pixels in row $j$. If $k$ signifies the number of $h_{1}$ values in the ideal edge, the first three sample moments between input and output sequences can be solved using three equations given by:

$$
\bar{m}_{i}=\sum_{j=1}^{2} p_{j} h_{j}^{i}
$$

where $i=1,2$ and 3, and $p_{h}$ is the number of pixels with grey intensity values $h$. With the three unknowns $h, k$ and $p_{2}$, the solutions of the edge are calculated by:

$$
\begin{gathered}
h_{1}=\bar{m}_{1}-\sigma \sqrt{\frac{p_{2}}{p_{1}}} \\
h_{2}=\bar{m}_{1}+\sigma \sqrt{\frac{p_{1}}{p_{2}}} \\
p_{2}=\frac{1}{2}\left[1+s \sqrt{\frac{1}{4+s^{2}}}\right]
\end{gathered}
$$




$$
p_{1}=1-p_{2}
$$

where $\sigma=\sqrt{\bar{m}_{2}-\bar{m}_{1}^{2}}$ and $s$ is the skewness of the input data sequence given by:

$$
S=\frac{2 \bar{m}_{1}+\bar{m}_{3}-3 \bar{m}_{1} \bar{m}_{2}}{\sigma^{3}}
$$

Thus, the location of the edge of workpiece up to sub-pixel accuracy is given by:

$$
k=p_{1} n
$$

The sub-pixel edge detection allows the precise edge location within fractional pixel coordinates (Fig. 1 a). This enables the nose edge profile to be extracted to a high degree of precision. The extracted nose edge was then duplicated along the feed direction using feed rate of $0.4 \mathrm{~mm} / \mathrm{rev}$ (Fig. $1 \mathrm{~b}$ ). Since the horizontal scaling factor $\left(f_{h}\right)$ determined using the pin gauge was $0.004296 \mathrm{~mm} /$ pixel, each nose edge profile was offset by 93 pixels. The edges of the pin gauge used to determine the scaling factor were also extracted using the sub-pixel edge detection method. A linear model was used to convert the image coordinates to real-world coordinates due to the minimum distortion present in the image $(0.16 \%)$. The curved nose edge responsible for forming the tool marks was extracted from the intersection points $A$ and $B$ (Fig. $1 \mathrm{~b})$ and duplicated 20 times to produce the simulated (ideal) workpiece profile as shown in Fig. $1 \mathrm{c}$. The average roughness $R_{a}$ was determined from the simulated profile using the following equation:

$$
R_{a}=\frac{1}{n} \sum_{i=1}^{n}\left|y_{i}\right| f_{v}
$$

where $y_{i}$ is the height of the profile above the mean line within a sampling (cut-off) length and $f_{v}$ is the vertical scaling factor $(0.004287 \mathrm{~mm} / \mathrm{pixel})$. The sampling length used for the roughness calculation was $0.8 \mathrm{~mm}$, typical in general turning operations.

The effect of adding vibration signals onto the simulated profiles were also investigated for profiles generated using worn cutting tool inserts. The extracted sub-pixel nose profiles at three different stages of machining are shown in Figs. 2 a - c.

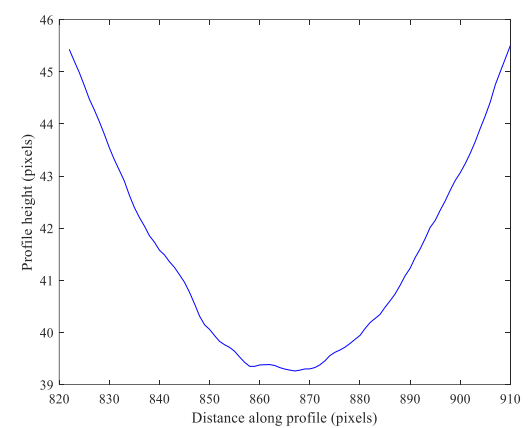

a)

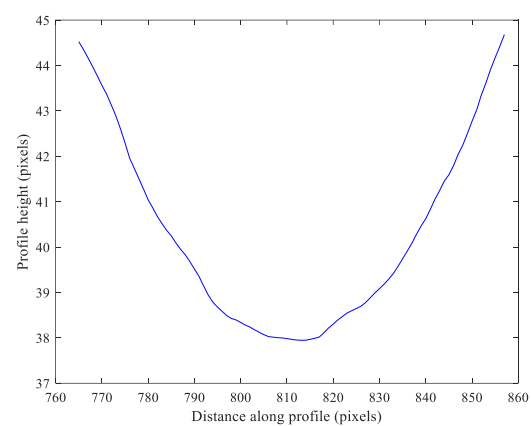

b)

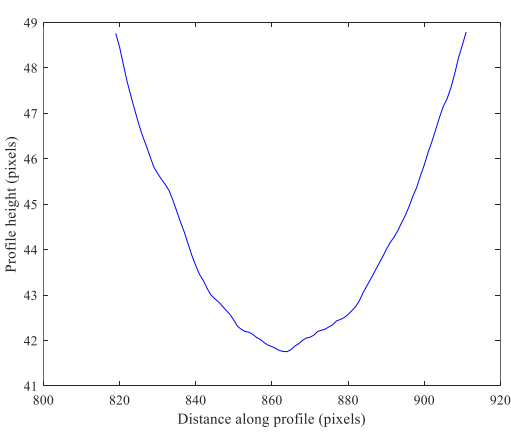

c)

Figure 2: Tool nose profile used to simulate workpiece at various stages of machining: a) $10 \mathrm{~min}$, b) $15 \mathrm{~min}$, and c) $20 \mathrm{~min}$.

\subsection{Introduction of vibration signal}

Vibration signal was generated using the simple sine wave function given by:

$$
y_{v}=A \sin 2 \pi f^{\prime} t
$$

where $A$ and $f$ ' are the vibration amplitude and frequency, respectively. In the simulation study, $A$ was varied between 0 to $50 \%$ of the peak-to-valley roughness $\left(R_{t o}\right)$ of the original simulated profile (without vibration) and was added digitally to the profile. The effect of adding a vibration signal of $20 \% R_{t o}$ and $f^{\prime}=50 \mathrm{~Hz}$ is illustrated in Figs. $3 \mathrm{a}-\mathrm{c}$. Fig. 3 a shows the original digitally generated workpiece profile, Fig. $3 \mathrm{~b}$ shows the vibration signal and Fig. $3 \mathrm{c}$ 
shows the result of adding vibration signal onto the original profile. All three subfigures were plotted using the same vertical axis range so that they can be compared. It is clear from the figure that the surface texture deteriorates after vibration is added, and the peak-to-valley roughness $\left(R_{t}\right)$ increases. For the case illustrated in Fig. 3, $R_{t}$ increased from 32.5 to $45.4 \mu \mathrm{m}$ (39.7\%), while $R_{a}$ increased from 8.5 to $9.0 \mu \mathrm{m}$ (5.9\%) after addition of vibration.

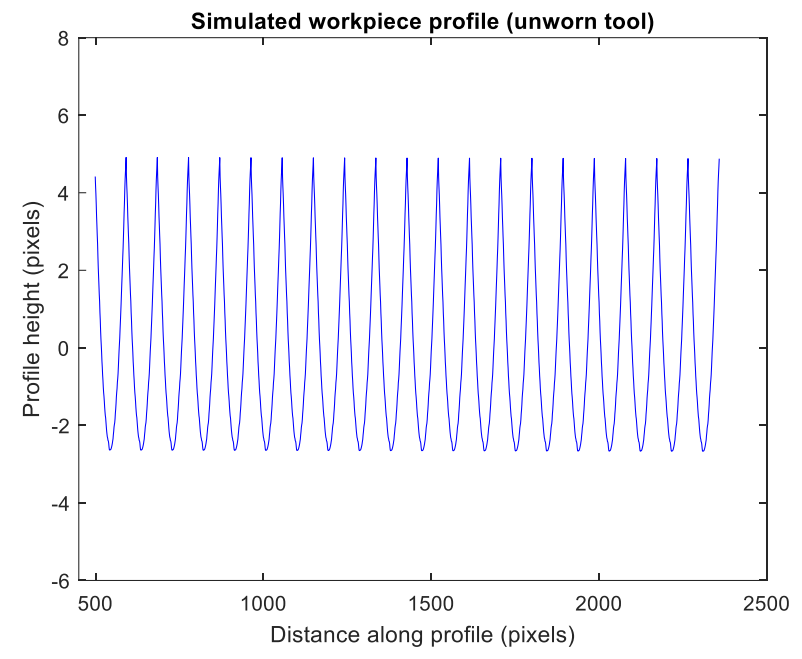

a)

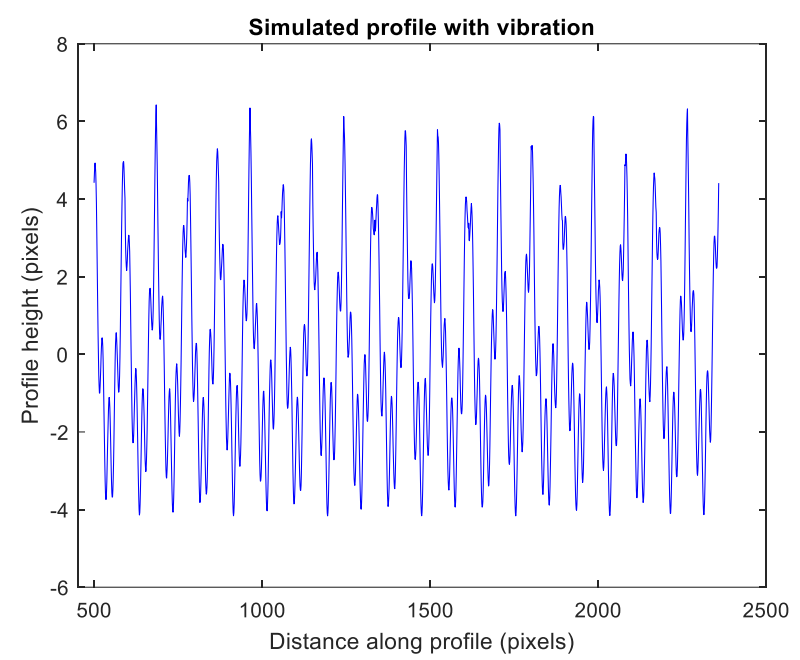

c)

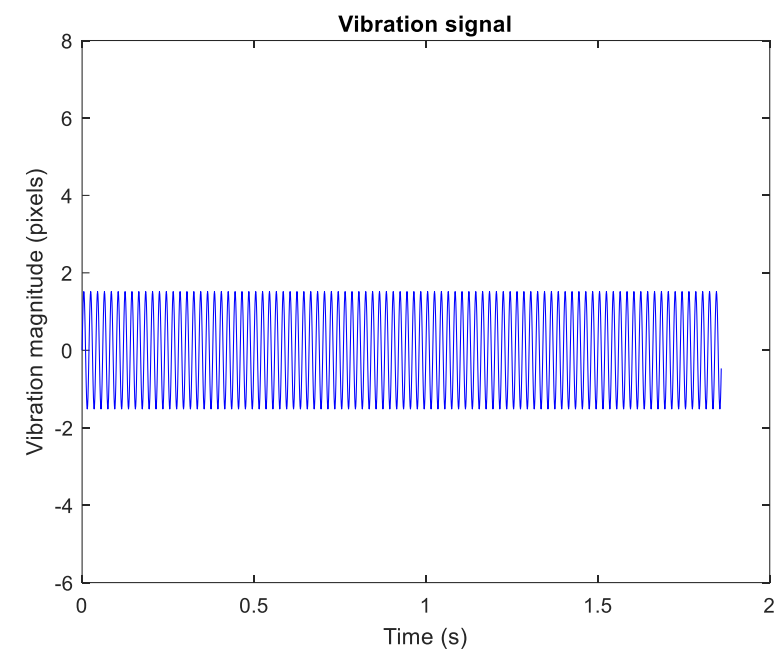

b)

Figure 3: a) Original digitally generated workpiece profile, b) sine wave vibration signal ( $A=20 \% R_{t o}$ and $f^{\prime}=50 \mathrm{~Hz}$ ), c) workpiece profile after addition of vibration signal.

The effect of adding vibration of various amplitudes and frequencies on $R_{a}$ and $R_{t}$ were investigated. While the vibration amplitude was varied from 0 to $50 \%$ of the peak-to-valley height of the original profile, the frequencies were varied between $50 \mathrm{~Hz}, 100 \mathrm{~Hz}$ and $150 \mathrm{~Hz}$. The effect of feed rates in the presence of vibration on $R_{a}$ and $R_{t}$ was also investigated by changing the feed from $0.2,0.3$ and $0.4 \mathrm{~mm} / \mathrm{rev}$. These feed values are used in typical turning operations. The effect of adding machining noise signal on these two roughness parameters was also investigated. The noise signal was obtained from a publicly available video footage of a lathe turning operation [25]. Fig. 4 a shows the vibration signal extracted from machining noise, while the result of adding the signal to the simulated workpiece profile generated using an unworn tool is shown in Fig. 4 b. The machining noise signal was amplified at different amplification levels to investigate the effect of magnitude of vibration on the surface roughness values. 


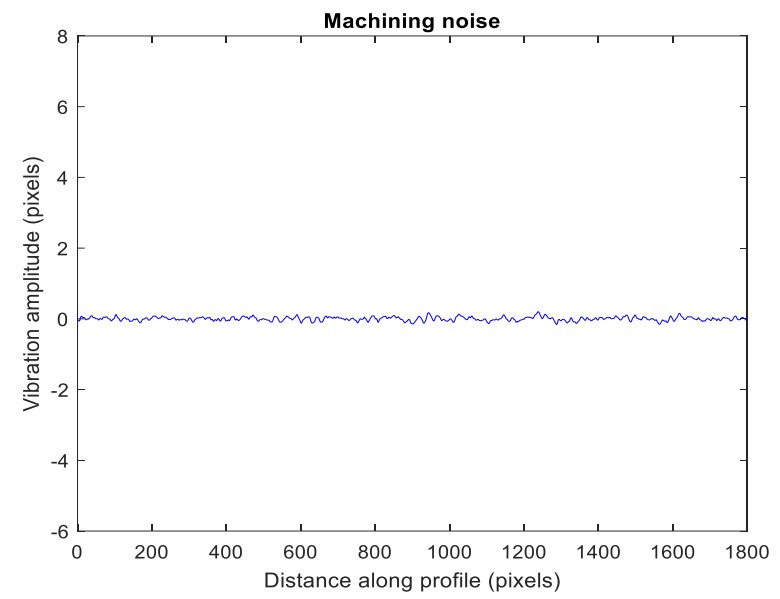

a)

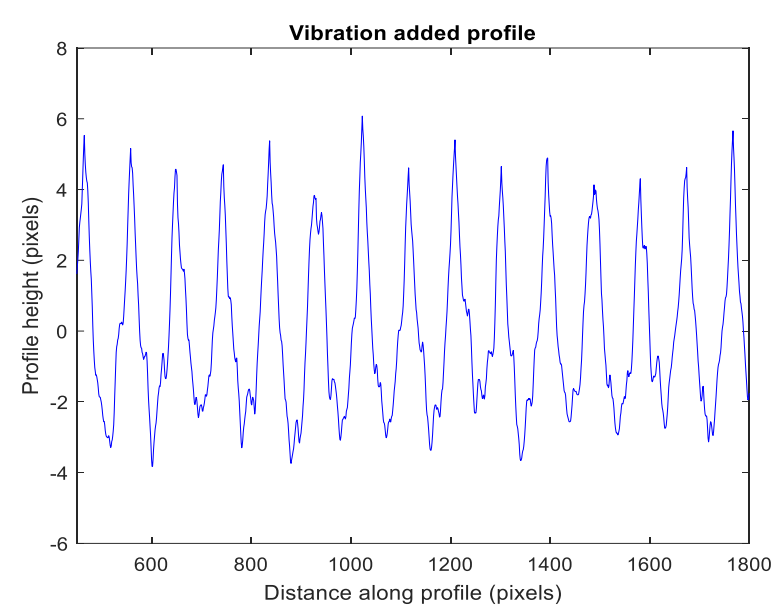

b)

Figure 4: a) Vibration signal from machining noise, b) simulated surface after addition of vibration.

\subsection{Comparison of simulated and real profiles}

In order to compare the simulated and real profiles, machining experiments were carried out on an AISI 316 stainless steel cylindrical bar with an initial diameter of 50 and length $350 \mathrm{~mm}$. The feed rate and spindle speeds were, respectively, $0.4 \mathrm{~mm} / \mathrm{rev}$ and $950 \mathrm{rpm}$. Images of the workpiece edge profile and cutting tool were capture using the DSLR digital camera with the aid of backlighting as in Fig. 1 a. The edge of the workpiece was also extracted using the subpixel edge detection method. The major flank wear was measured after every five passes (2.5 minutes of machining) of the tool using a scanning electron microscope (Hitachi Tabletop Microscope TM-1000) installed with measurement software. The wear measurement was done after every five passes due to the low rate of wear of the carbide insert.

\section{RESULTS AND DISCUSSION}

\subsection{Effect of vibration amplitude and frequency on profile generated using unworn tool}

The effect of adding simple sine-wave vibration of various amplitudes and frequencies to the surface simulated using an unworn tool at feed spacing of $0.4 \mathrm{~mm}$ on $R_{a}$ and $R_{t}$ are shown, respectively, in Figs. $5 \mathrm{a}$ and b. The $R_{a}$ value can be seen to increase gradually with the increase in the vibration amplitude, with an approximately quadratic relationship. It is interesting to note that $R_{t}$ increases approximately linearly with increase in the vibration amplitude. This is due to the linear increase in the vibration amplitude, which increases the peak-to-valley height in a likewise linear manner. In both cases, however, the vibration frequency was found to have very little influence on the roughness parameters.

The effect of vibration amplitude on $R_{a}$ and $R_{t}$ at three different feed rates $(0.2,0.3$ and 0.4 $\mathrm{mm} / \mathrm{rev}$ ) are shown in Figs. $6 \mathrm{a}$ and b, respectively. At lower feed rates the effect of increased vibration amplitudes is not as significant as that at the highest feed rate of $0.4 \mathrm{~mm} / \mathrm{rev}$. At the feed rate of $0.3 \mathrm{~mm} / \mathrm{rev} R_{a}$ increased by a maximum of $52 \%$ for increase in vibration amplitude from 0 to $50 \%$. The corresponding increase in $R_{t}$ was $79 \%$, suggesting that vibration has a dominant effect on the peak-to-valley roughness. Vibration appears to have a lower effect on both $R_{a}$ and $R_{t}$ at lower feed rates compared to higher feed rates. At higher feed rates the feed marks are more pronounced with dominant peaks and valleys, whose morphology is more greatly affected by vibration.

The effect of feed rate at various amplitudes of vibration on $R_{a}$ is shown in Fig. 7. As expected, $R_{a}$ increased with feed rate because these variables are related by a quadratic function given by the approximate theoretical value [26]: 


$$
R_{a}=0.032 \frac{f^{2}}{r}
$$

where $r$ is the tool nose radius. The highest values of $R_{a}$ and $R_{t}$ were observed at the highest vibration amplitude, implying that the surface roughness of the workpiece is significantly affected by the amplitude of the vibration during turning.

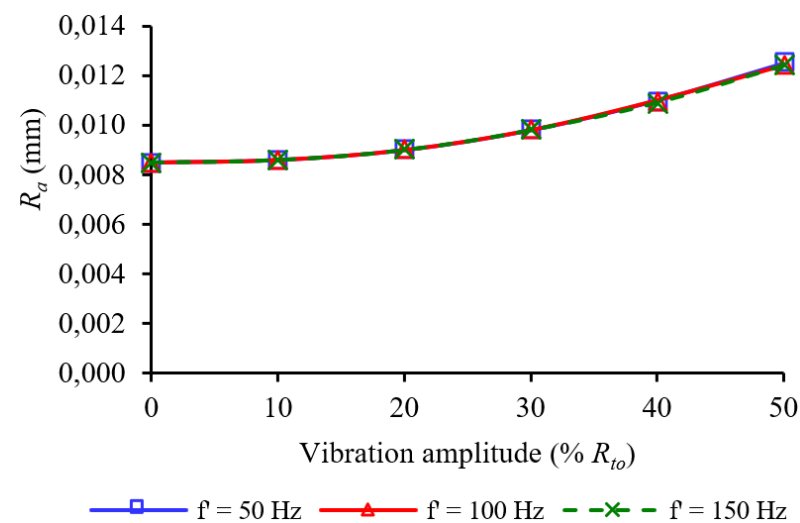

a)

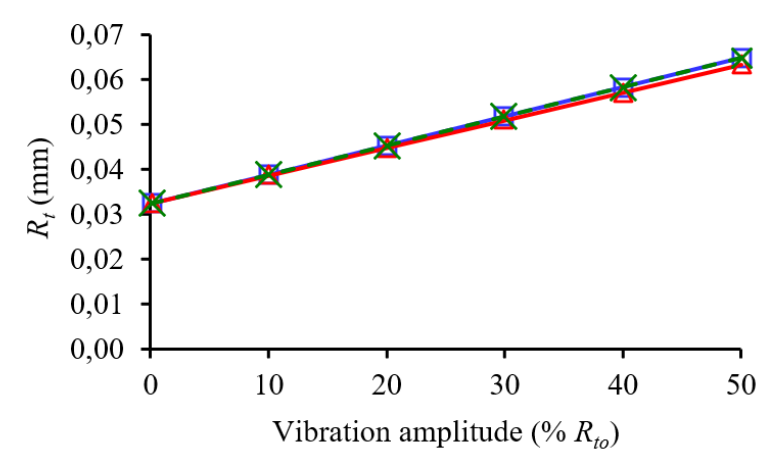

b)

Figure 5: Effect of vibration amplitude and frequency on a) $R_{a}$ and b) $R_{t}$.

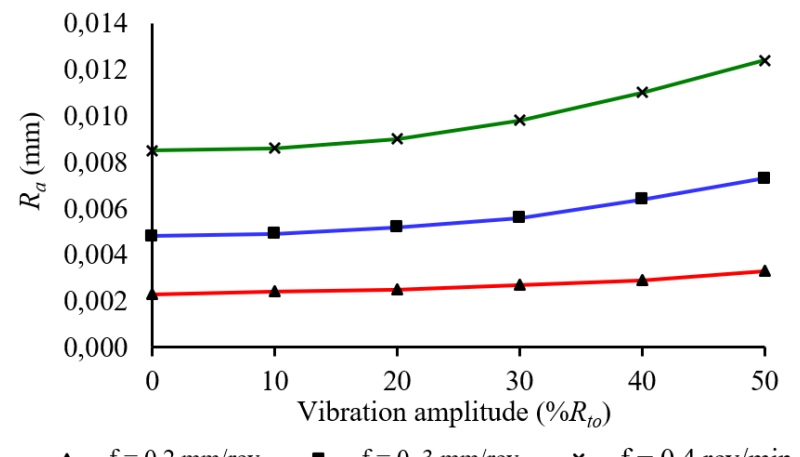

a)

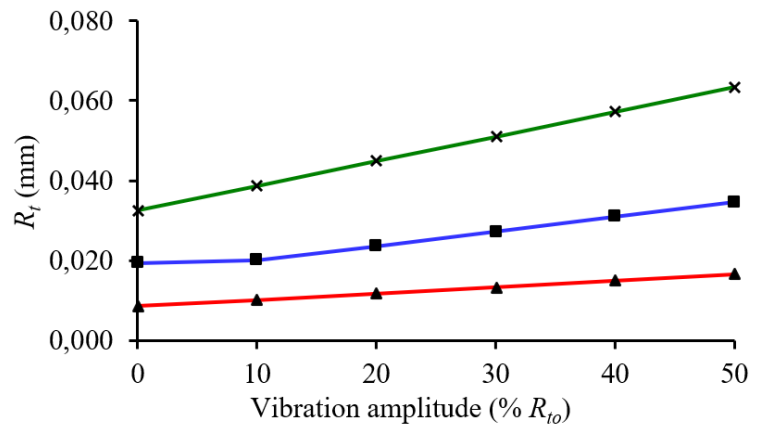

b)

Figure 6: Effect of vibration amplitude and feed rate on a) $R_{a}$ and b) $R_{t}$.

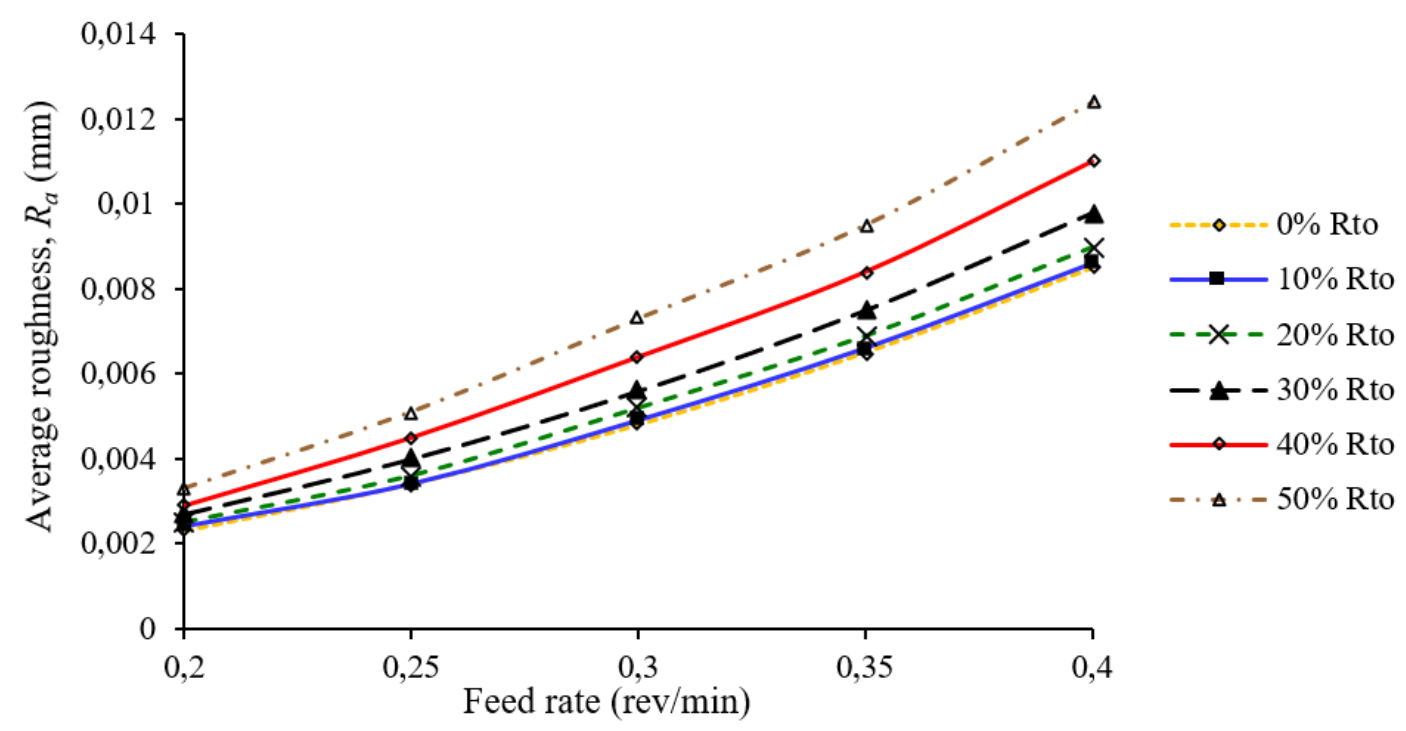

Figure 7: Effect of feed rate on $R_{a}$ roughness at various vibration levels. 
The effect of machining time on roughness at various amplitudes of vibration on $R_{a}$ and $R_{t}$ are shown in Figs. 8 a and b, respectively. The roughness value appears to fluctuate randomly without any obvious trend with the machining time, although flank wear increased during this duration as shown in Fig. 9. Similar observations were reported by Niaki and Mears [5] during dry turning. The lack of correlation between roughness and tool wear at various machining times could be due to the limitations of the $R_{a}$ parameter which, being an amplitude parameter, is insensitive to the lateral changes undergone by the surface. $R_{a}$ may also not be sensitive enough to detect the slight fluctuations in the roughness profile caused by vibration due to the averaging effect. Although fluctuations in $R_{a}$ and $R_{t}$ somewhat remains the same, the magnitude of roughness values at any particular machining time increased with the vibration amplitude.

Unlike the analysis results in Fig. 8, whereby the vibration amplitude was fixed throughout the machining time, Fig. 10 shows the effect of increasing the vibration amplitude with machining time on $R_{a}$. In this simulation, the sine wave vibration amplitude was increased by $10 \%$ at each 10 minutes of machining time by considering the fact that vibration generally increased as the tool gets worn out, as found experimentally by several researchers $[9,10]$. It can be observed that both $R_{a}$ and $R_{t}$ increased continuously with machining time. Thus, the results in Fig. 10 can be used to explain the continuous increase in roughness with machining time as observed by Khan et al. [6] and Sani et al. [7], which is likely due to a significant increase in the vibration amplitude as the tool gets increasingly worn.

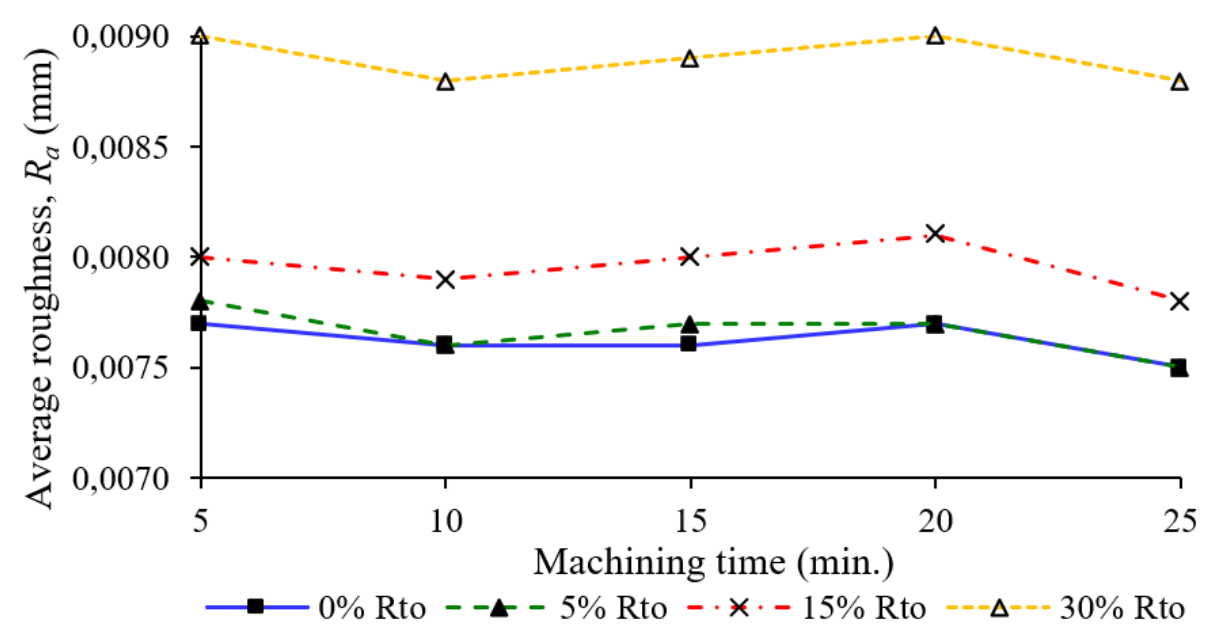

a)

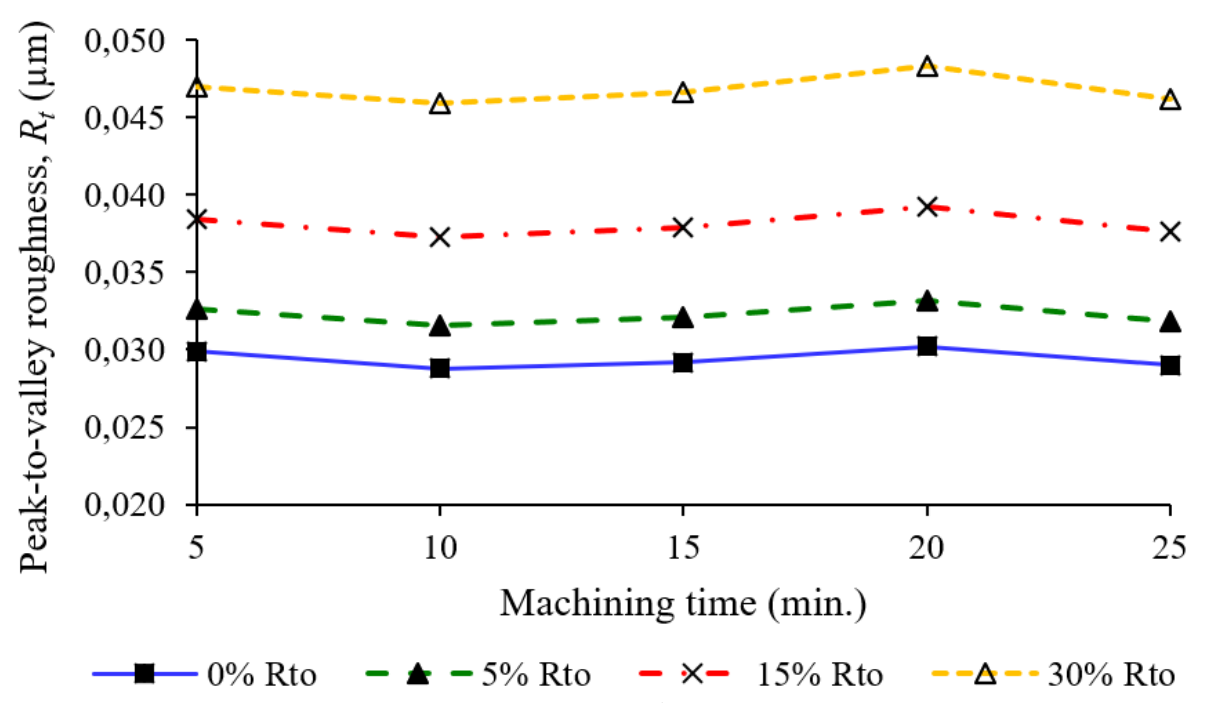

b)

Figure 8: Effect of wear and vibration amplitude on surface roughness: a) $R_{a}$, b) $R_{t}$. 


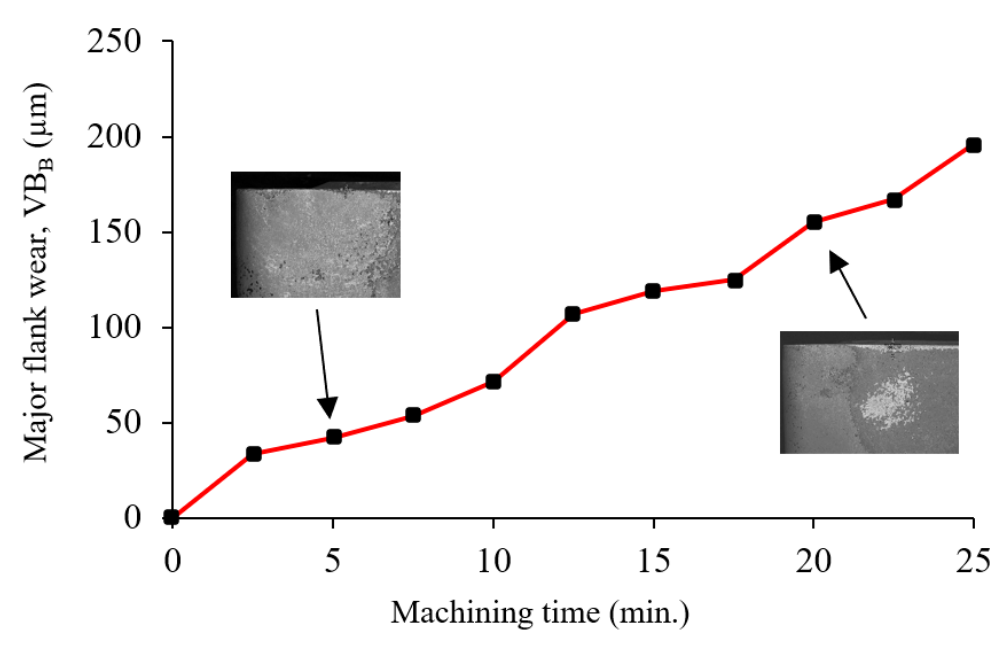

Figure 9: Variation of major flank wear with machining time.

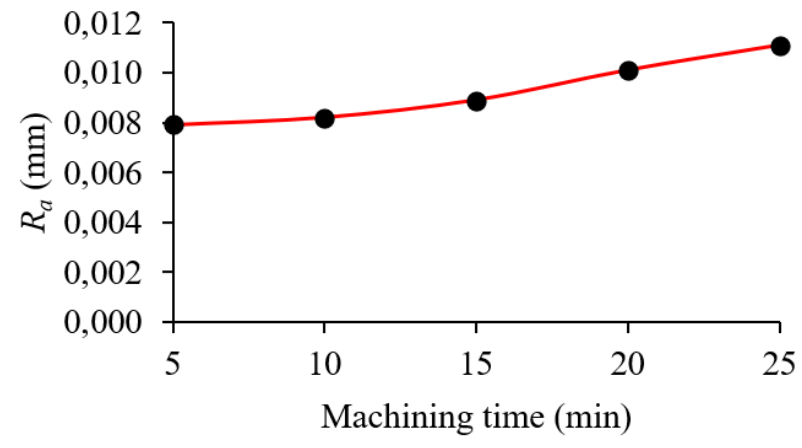

a)

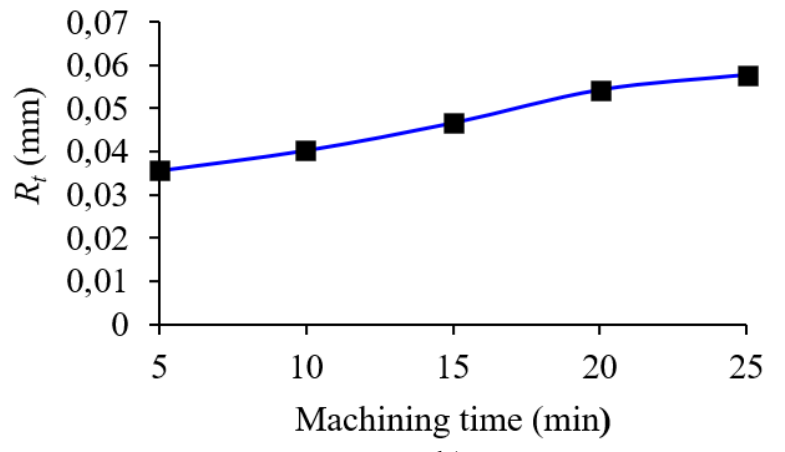

b)

Figure 10: Effect of machining time on surface roughness (increasing vibration at $5 \mathrm{~min}$. interval).

The effect of adding real vibration signals extracted from machining noise at various amplification factors $(0 \times$ to $50 \times)$ to the simulated profile is shown in Figs. $11 \mathrm{a}$ and b. Fig. $11 \mathrm{a}$ shows that when the magnitude of random vibration signal increases, $R_{a}$ increases approximately as a quadratic function of the amplification factor. However, $R_{t}$ increases linearly as seen in Fig. $11 \mathrm{~b}$. The rapid increase in the average roughness is due to the increased fluctuation in the profile as the amplification factor increases as seen in Figs. $12 \mathrm{a}$ and $\mathrm{b}$. Fig. 13 shows the results obtained by Khan et al. [6], whereby $R_{a}$ increased continuously with machining time. The higher $R_{a}$ values observed during dry turning could be directly due to the increased vibration resulting from higher flank wear. Comparison of Figs. 13 and 11 a indicates that the quadratic increase in $R_{a}$ could, indeed, be caused by increase in vibration.

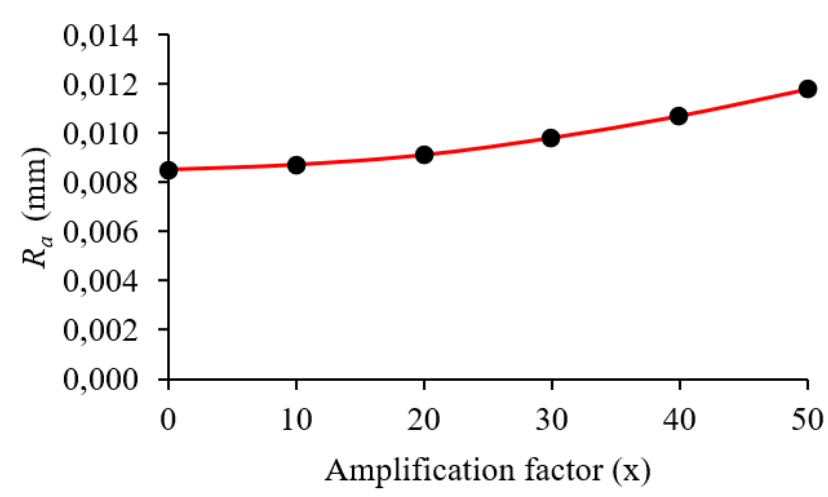

a)

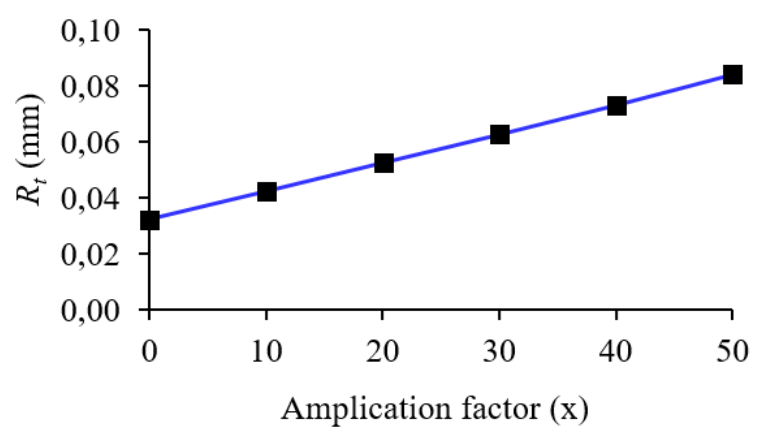

b)

Figure 11: Effect of amplification factor on roughness value: a) $R_{a}$, b) $R_{t}$. 


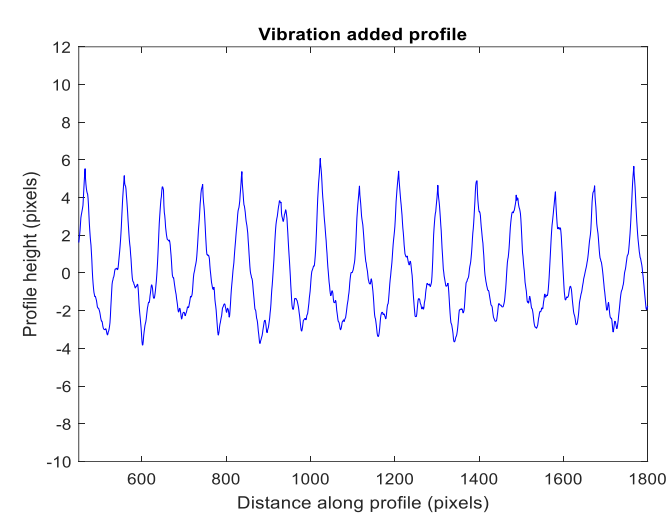

a)

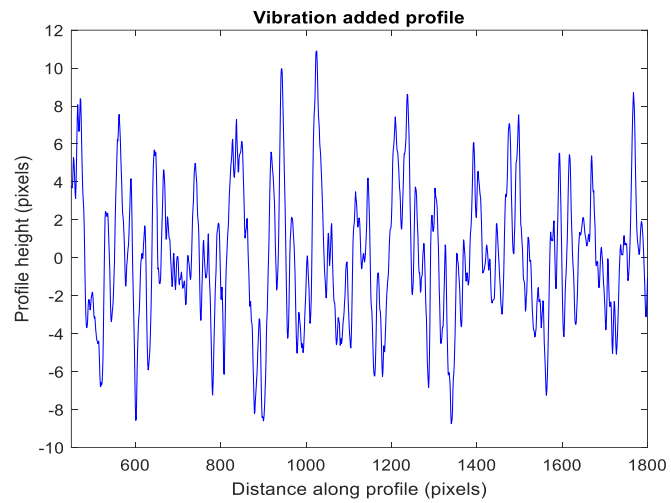

b)

Figure 12: Roughness profiles at: a) $10 \times$ amplification, b) 50× amplification.

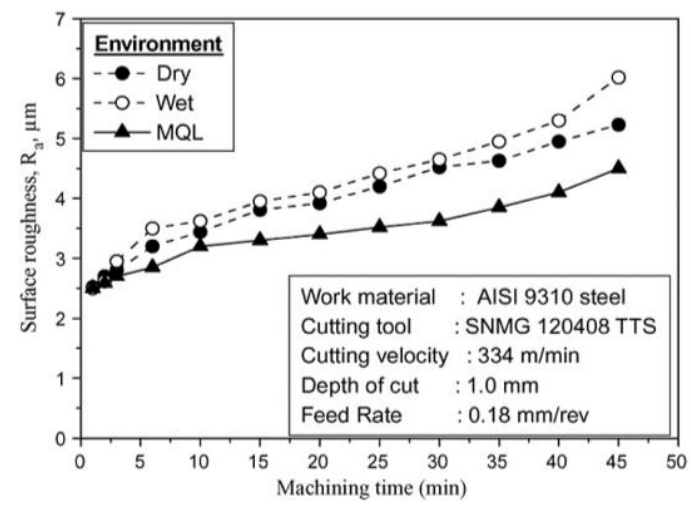

Figure 13: Variation in surface roughness with progress of turning steel by SNMG insert under different cooling conditions [6].

Fig. 14 a shows the real profile extracted from the workpiece surface after 20 passes of cutting tool (10 minutes of machining time), while Fig. $14 \mathrm{~b}$ shows the profile simulated from the cutting tool nose after the 20 passes. The real profile clearly shows low-frequency fluctuations due to vibration during the machining, thus resulting in higher peak-to-valley roughness. Vibration, however, may not have a significant effect on the average roughness. In the case shown in Fig. 14 a, the average roughness is $7.1 \mu \mathrm{m}$ while the peak-to-valley roughness is $34.2 \mu \mathrm{m}$. The corresponding roughness values for the simulated profiles were $R_{a}=7.2 \mu \mathrm{m}$ and $R_{t}=27.4 \mu \mathrm{m}$. The low-frequency vibration, therefore, has a lower effect on $R_{a}$ (roughness value dropped by $1.4 \%$ ) compared to its effect on $R_{t}$, whereby the roughness increased by $25 \%$.

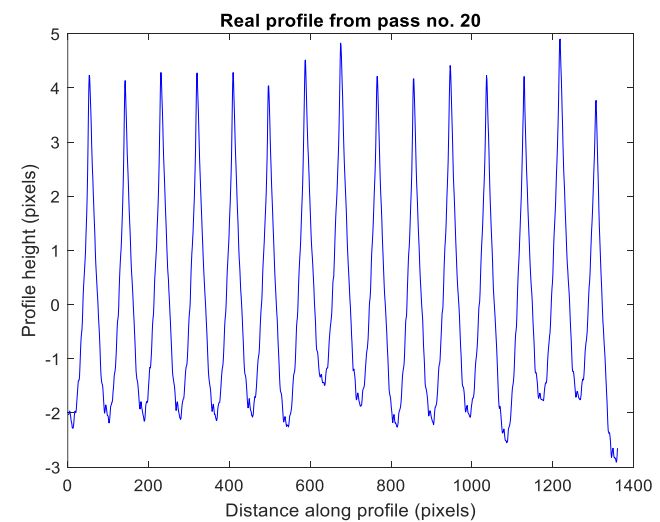

a)

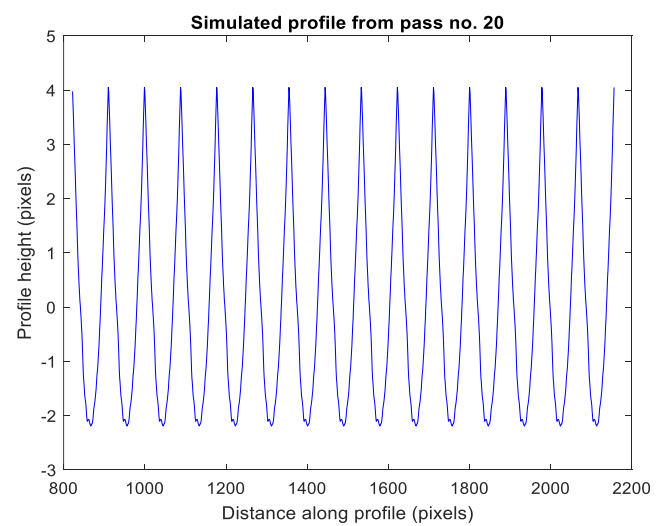

b)

Figure 14: a) Real roughness profile after 20 passes of cutting tool, b) roughness profile simulated using tool nose after 20 passes. 


\section{CONCLUSION}

The effects of controlled vibration amplitudes and frequencies on average roughness $\left(R_{a}\right)$ and peak-to-valley roughness $\left(R_{t}\right)$ were investigated using simulation. The surface profiles used in the roughness analyses were simulated using the tool nose profile of actual cutting tool at various stages of wear. The study has revealed that vibration amplitude has a major influence on the surface roughness, whereas the vibration frequency has minimal effect. The increase in vibration magnitude with increasing tool wear increases the roughness value. The results of the simulation could explain the continuous increases in $R_{a}$ observed by several researchers in the past, whereby the increasing tool wear increases vibration amplitudes, thus causing a corresponding increase in $R_{a}$. In the presence of stable vibration, however, $R_{a}$ may fluctuate with machining time.

\section{ACKNOWLEDGEMENT}

This work was partly supported by the Universiti Sains Malaysia (USM) Research University (RUI) grant (Grant no. 1001.PMEKANIK.8014013).

\section{REFERENCES}

[1] Sterpin Valic, G.; Cukor, G.; Jurkovic, Z.; Brezocnik, M. (2019). Multi-criteria optimization of turning of martensitic stainless steel for sustainability, International Journal of Simulation Modelling, Vol. 18, No. 4, 632-642, doi:10.2507/IJSIMM18(4)495

[2] De Almeida, F. A.; Gomes, G. F.; De Paula, V. R.; Corrêa, J. E.; De Paiva, A. P.; De Freitas Gomes, J. H.; Turrioni, J. B. (2018). A weighted mean square error approach to the robust optimization of the surface roughness in an AISI 12L14 free-machining steel-turning process, Strojniski vestnikJournal of Mechanical Engineering, Vol. 64, No. 3, 147-156, doi:10.5545/sv-jme.2017.4901

[3] Ratnam, M. M. (2017). Factors affecting surface roughness in finish turning, Hashmi, M. S. J. (Ed.), Reference Module in Materials Science and Materials Engineering, Comprehensive Materials Finishing, Vol. 1, 1-25, doi:10.1016/B978-0-12-803581-8.09147-5

[4] Shahabi, H. H.; Ratnam, M. M. (2009). In-cycle monitoring of tool nose wear and surface roughness of turned parts using machine vision, International Journal of Advanced Manufacturing Technology, Vol. 40, No. 11-12, 1148-1157, doi:10.1007/s00170-008-1430-8

[5] Niaki, F. A.; Mears, L. (2017). A comprehensive study on the effects of tool wear on surface roughness, dimensional integrity and residual stress in turning IN718 hard-to-machine alloy, Journal of Manufacturing Processes, Vol. 30, 268-280, doi:10.1016/j.jmapro.2017.09.016

[6] Khan, M. M. A.; Mithu, M. A. H.; Dhar, N. R. (2009). Effects of minimum quantity lubrication on turning AISI 9310 alloy steel using vegetable oil-based cutting fluid, Journal of Materials Processing Technology, Vol. 209, No. 15-16, 5573-5583, doi:10.1016/j.jmatprotec.2009.05.014

[7] Sani, A. S. A.; Rahim, E. A.; Sharif, S.; Sasahara, H. (2019). The influence of modified vegetable oils on tool failure mode and wear mechanisms when turning AISI 1045, Tribology International, Vol. 129, 347-362, doi:10.1016/j.triboint.2018.08.038

[8] Zhang, S. J.; To, S.; Zhang, G. Q.; Zhu, Z. W. (2015). A review of machine-tool vibration and its influence upon surface generation in ultra-precision machining, International Journal of Machine Tools and Manufacture, Vol. 91, 34-42, doi:10.1016/j.ijmachtools.2015.01.005

[9] Özbek, O.; Saruhan, H. (2020). The effect of vibration and cutting zone temperature on surface roughness and tool wear in eco-friendly MQL turning of AISI D2, Journal of Materials Research and Technology, Vol. 9, No. 3, 2762-2772, doi:10.1016/j.jmrt.2020.01.010

[10] García Plaza, E.; Núñez López, P. J. (2017). Surface roughness monitoring by singular spectrum analysis of vibration signals, Mechanical Systems and Signal Processing, Vol. 84, Part A, 516-530, doi:10.1016/j.ymssp.2016.06.039

[11] García Plaza E.; Núñez López, P. J. (2018). Application of the wavelet packet transform to vibration signals for surface roughness monitoring in CNC turning operations, Mechanical Systems and Signal Processing, Vol. 98, 902-919, doi:10.1016/j.ymssp.2017.05.028 
[12] Horváth, R.; Lukács, J. (2017). Application of a force model adapted for the precise turning of various metallic materials, Strojniski vestnik - Journal of Mechanical Engineering, Vol. 63, No. 9, 489-500, doi:10.5545/sv-jme.2017.4430

[13] Özdemir, M. (2020). Modelling and prediction of effect of machining parameters on surface roughness in turning operations, Technical Gazette, Vol. 27, No. 3, 751-760, doi:10.17559/TV20190320104114

[14] Rifai, A. P.; Aoyama, H.; Tho, N. H.; Md Dawal, S. Z.; Masruroh, N. A. (2020). Evaluation of turned and milled surfaces roughness using convolutional neural network, Measurement, Vol. 161, Paper 107860, doi:10.1016/j.measurement.2020.107860

[15] Mia, M.; Dhar, N. R. (2016). Prediction of surface roughness in hard turning under high pressure coolant using Artificial Neural Network, Measurement, Vol. 92, 464-474, doi:10.1016/ j.measurement.2016.06.048

[16] Abouelatta, O. B.; Mádl, J. (2001). Surface roughness prediction based on cutting parameters and tool vibrations in turning operations, Journal of Materials Processing Technology, Vol. 118, No. 1-3, 269-277, doi:10.1016/S0924-0136(01)00959-1

[17] He, C. L.; Zong, W. J.; Zhang, J. J. (2018). Influencing factors and theoretical modeling methods of surface roughness in turning process: State-of-the-art, International Journal of Machine Tools and Manufacture, Vol. 129, 15-26, doi:10.1016/j.ijmachtools.2018.02.001

[18] Upadhyay, V.; Jain, P. K.; Mehta, N. K. (2013). In-process prediction of surface roughness in turning of Ti-6Al-4V alloy using cutting parameters and vibration signals, Measurement, Vol. 46, No. 1, 154-160, doi:10.1016/j.measurement.2012.06.002

[19] Wang, H.; To, S.; Chan, C. Y. (2013). Investigation on the influence of tool-tip vibration on surface roughness and its representative measurement in ultra-precision diamond turning, International Journal of Machine Tools and Manufacture, Vol. 69, 20-29, doi:10.1016/ j.ijmachtools.2013.02.006

[20] Risbood, K. A.; Dixit, U. S.; Sahasrabudhe, A. D. (2003). Prediction of surface roughness and dimensional deviation by measuring cutting forces and vibrations in turning process, Journal of Materials Processing Technology, Vol. 132, No. 1-3, 203-214, doi:10.1016/S09240136(02)00920-2

[21] Swain, S.; Chattarjee, S.; Panigrahi, I.; Sahoo, A. K. (2018). Cutting tool vibration analysis for better surface finish during dry turning of mild steel, Materials Today: Proceedings, Vol. 5, No. 11, Part 3, 24605-24611, doi:10.1016/j.matpr.2018.10.258

[22] Kessentini, A.; Zghal, B.; Karra, C.; Louati, J.; Haddar, M. (2006). Simulation and modelling of the vibration effect on the hole form in drilling, International Journal of Simulation Modelling, Vol. 5, No. 4, 133-144, doi:10.2507/IJSIMM05(4)1.070

[23] Khajehzadeh, M.; Boostanipour, O.; Razfar, M. R. (2020). Finite element simulation and experimental investigation of residual stresses in ultrasonic assisted turning, Ultrasonics, Vol. 108, Paper 106208, 32 pages, doi:10.1016/j.ultras.2020.106208

[24] Tabatabai, A. J.; Mitchell, O. R. (1984). Edge location to subpixel values in digital imagery, IEEE Transactions on Pattern Analysis and Machine Intelligence, Vol. 6, No. 2, 188-201, doi:10.1109/TPAMI.1984.4767502

[25] Braddock, M. Turning Process Overview, from https://www.youtube.com/watch?v=J3wN1ruDZM, accessed on 23-06-2020

[26] Qu, J.; Shih, A. J. (2003). Analytical surface roughness parameters of a theoretical profile consisting of elliptical arcs, Machining Science and Technology, Vol. 7, No. 2, 281-294, doi: $\underline{10.1081 / \mathrm{MST}-120022782}$ 